JOURNAL OF CIVIL ENGINEERING AND MANAGEMENT

http:/www.vtu.lt/english/cditions

2003, Vol IX, No 1, 45-51

\title{
THE INFLUENCE OF MORTAR MICROSTRUCTURE ON ITS THERMAL EXPAN-
} SION COEFFICIENT

\author{
Darius Zabulionis ${ }^{1}$, Gediminas Marčiukaitis ${ }^{2}$ \\ 'Dept of Building Materials, Vilnius Gediminas Technical University, Sauletekio al. 11, LT-2040 Vilnius, Lithuania. \\ E-mail: stsm@st.vtu.lt \\ ${ }^{2}$ Dept of Reinforced Concrete and Masonry Structures, Vilnius Gediminas Technical University, Sauletekio al. 11, \\ LT-2040VVilnius, Lithuania.E-mail: gelz@st.vtu.lt
}

Received 02 Febr 2002; accepted 09 Jan 2003

\begin{abstract}
Thermal strain is one of the factors causing additional stresses in a composite structure. It is necessary to calculate the coefficient of thermal expansion in evaluating thermal strains. According to the research, concrete is a material consisting of three phases: aggregate, interfacial transition zone (ITZ) and cement paste. The article presents the technique which enables the estimation of the thermal expansion coefficient of the mortar consisting of various aggregate fractions and covered with ITZ layer. A parametric study of various ITZ layer characteristics influencing the coefficient of thermal expansion has been carried out in the present paper. It has been determined that dry mortar or concrete could be treated as a material consisting of two components. While evaluating moist mortar or concrete it is necessary to take into account the depth of the ITZ the bulk modulus and the coefficient of thermal expansion.
\end{abstract}

Keywords: mortar, concrete, interfacial transit zone, modulus of elasticity, coefficient of thermal expansion.

\section{Introduction}

In most building structures the restrained strains can be observed. Temperature variation can cause stresses exceeding the ultimate strength of the material. This may lead to the formation of various flaws in structures, ie cracking of plaster layers [1-4] in a building as well as of the walls themselves [3]. To calculate the stresses caused by thermal strains, the coefficient of thermal expansion of the material (a) should be known.

The coefficient $\alpha$ for mortars and concretes is usually found by testing. A test aimed to determine the influence of various factors on the coefficient of thermal expansion is carried out according to a particular design. However, this method has some drawbacks. It is well known that $\alpha$ of the mortar depends not only on its constituent parts, their amount and properties but on mortar microstructure and interaction of the particular fractions as well. The application of an experimental technique can hardly help determine the role of all the factors involved.

An altemative approach to determining $\alpha$ of the mor$\operatorname{tar}$ is based on the theory of composites [5-10]. This method is more advanced because it allows us to determine analytically the amount of the component materials, their properties as well as the effect of mortar porosity and microstructure on the value of $\alpha$.

Based on the above theory, mortar is usually assumed to be a two-component material consisting of matrix, ie cement rock, and aggregate. However, the tests [6-8] have shown that a layer of cement rock is formed around any aggregate, with its main properties different from those of the matrix. In some papers $[5,11]$, this layer is referred to as interfacial transition zone (ITZ). It has been shown $[5,12-14]$ that ITZ can considerably affect physical and mechanical properties of mortar. Analytic and experimental research conducted has shown that in terms of the modulus of elasticity, shrinkage, permeability of liquids and gases, concrete or mortar can hardly be considered a material consisting merely of such components as aggregate and cement rock. The effect of ITZ should also be taken into account. However, the data on the influence of this zone on $\alpha$ of the material is very scarce.

Therefore, in the present investigation a four-phase model [8] for calculating thermal strains of concrete and mortar based on ITZ, matrix and the respective equivalent environment has been accepted.

\section{A geometric model of concrete and mortar micro- structure}

As we know, concrete and mortar are not structurally homogeneous. The porosity of ITZ surrounding the aggregate may be either higher or lower than the matrix porosity [14]. This difference diminishes proportionally to the distance of the material from the aggregate surface, being eliminated when ITZ porosity finally reaches 
matrix porosity [11-13]. In Portland cement concrete and mortar, a non-homogeneous layer of $\mathrm{Ca}(\mathrm{OH})_{2}$ crystals is formed around the aggregate. In this case, ITZ has a higher concentration of $\mathrm{Ca}(\mathrm{OH})_{2}$ crystals and a lower gel concentration as well as a higher porosity and a lower hydrated cement [11-13].

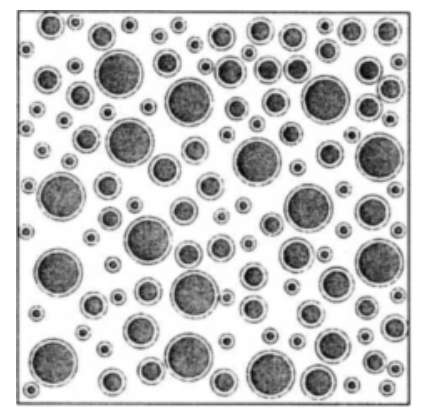

Fig 1. Model of mortar microstructure: $\square$ - cement paste, aggregate, - interfacial transition zone (ITZ)

For the sake of calculation simplification it is assumed that the aggregate particles are of a regular spherical shape, the properties of ITZ do not vary throughout the layer and the granules of aggregate do not interact. Further, three phases of mortar, ie cement rock or matrix, ITZ and aggregates will be considered (Fig 1).

\section{Analytic equations for calculating the coefficient of thermal expansion}

A formula suggested in [5] for calculating the coefficient $\alpha$ allows us to do calculations for any number of coats. However, it may be applied only for a small amount of aggregate $(0,1-0,2$ parts by volume), while in actual concrete or mortar aggregate makes $40-85 \%$. Therefore, this technique is not applicable. For similar reasons $[6,7]$, other methods suggested for calculations are not suitable either. One of the above methods is based on the relationships between bulk modulus and thermal expansion coefficient for considerably larger amount of aggregate in mortar or concrete [8], since the effect of the matrix bulk on the bulk modulus and $\alpha$ of mortar is to be assessed. However, the calculation technique suggested in [8] may be applied only to mortar with aggregate particles of uniform size. The calculating method suggested here can evaluate the effect of various size aggregate on the thermal expansion coefficient of mortar or concrete.

The whole bulk of mortar or concrete may be divided into parts, the number of which is equal to that of various fractions found in the particular type of aggregate. For any fraction, the size of aggregate is assumed to be constant. Then, the bulk modulus of the $i$-th part of mortar corresponding to the $i$-th fraction of aggregate may be calculated (based on [8]) from the formulas given below:

$$
\begin{gathered}
K_{p, i}=K_{i t z}+\frac{\left(K_{\mathrm{a}}-K_{i t z}\right)\left(a_{i} b_{i}\right)^{3}}{1+K_{\mathrm{a}}-K_{i t z_{-}}\left(1-\left(a_{i} b_{i}\right)^{3}\right)}, \\
K_{i t z}+43 G_{i t z}\left(K_{p, i}-K_{m}\right) c_{i} \\
1+\frac{K_{p, i}-K_{m}}{K_{m}+4 / 3 G_{m}}\left(1-c_{i}\right)
\end{gathered}
$$

here $K_{m}, K_{i t z}, K_{a}, K_{m r t, i}, K_{p, I}$ are bulk modulus of the matrix, ITZ, aggregate, $i$-th part of mortar and its aggregate including ITZ; $G_{i t r}, G_{m}$ - shear modulus of ITZ and the matrix; $a_{i}, b_{i}$-diameter of the aggregate and aggregate plus ITZ, respectively, $c_{i}$ - a part of aggregate volume plus ITZ volume part. It is well known that the bulk modulus of a homogeneous isotropic material may be calculated from the formula $K=E /(3(1-2 v))$; here $E-$ bulk modulus, $v$ - Poisson's ratio.

The thermal expansion coefficient of aggregate plus ITZ is as follows:

$$
\begin{aligned}
& \alpha_{p, i}=\alpha_{i t z}+\frac{\alpha_{a}-\alpha_{i t z}}{\frac{1}{K_{a}}-\frac{1}{K_{i t z}}}\left(\frac{1}{K_{p, i}}-\frac{1}{K_{i t z}}\right), \\
& \alpha_{m r t, i}=\alpha_{m}+\frac{\alpha_{p, i}-\alpha_{m}}{\frac{1}{K_{p, i}}-\frac{1}{K_{m}}}\left(\frac{1}{K_{m r t, i}}-\frac{1}{K_{m}}\right)
\end{aligned}
$$

here $\alpha_{m}, \alpha_{i t z}, \alpha_{a}, \alpha_{m r t, i}, \alpha_{p, i}$ are thermal expansion coefficients of matrix, ITZ, aggregate, the $i$-th part of mortar volume and its aggregate plus ITZ, respectively.

The analysis of formulas $(1-4)$ has shown that the calculated value of $\alpha$ for the mortar parts depends both on the bulk modulus and $\alpha$ of the components and the relationship between the diameters of the aggregate and aggregate plus ITZ. Therefore, it should be known what part of the total volume of concrete or mortar falls at (corresponds to) an individual fraction. If a composite is made up of $\mathrm{n}$ fractions, $V_{i}$ is the $i$-th fraction of aggregate, while $V_{i}^{\prime}$ is a part of mortar volume corresponding to the $i$-th aggregate fraction. Then it may be stated that the relationship between the $i$-th aggregate fraction and the sum of the rest fractions is equal to the relationship between the $i$-th part of mortar volume and the sum of the rest parts of mortar volume:

$$
\sum_{j=1}^{n} V_{j}-V_{i} \sum_{j=1}^{n} V_{j}^{\prime}-V_{i}^{\prime}=k_{i}
$$

The equation (5) yields:

$$
V_{i}^{\prime}=k_{i}\left(\sum_{j=1}^{n} V_{j}^{\prime}-V_{i}^{\prime}\right)
$$


Having solved (6) and equalised $\sum_{j=1}^{n} V_{j}^{\prime}$ to 1 , since the sum of the mortar volume parts is equal to 1 [9], we obtain that the $i$-th aggregate fraction corresponding to the $i$-th mortar volume part is equal to:

$$
V_{i}^{\prime}=\begin{gathered}
k_{i} \\
1+k_{i}
\end{gathered},
$$

here $k_{i}$ - coefficient obtained from equation (5).

Then, taking into account (5) and (7), the fraction of aggregate corresponding to the $i$-th part of mortar volume will be equal to:

$$
V_{a, i}=\frac{V_{i}}{V_{i}^{\prime}}=V_{a}=\sum_{i=1}^{n} V_{i} .
$$

In order to calculate the coefficient of thermal expansion by the formulas $(1-4)$, we should know the part of volume corresponding to ITZ. In literature, two methods $[5,15]$ of determining the volume part of ITZ can be found. According to (15), the volume of ITZ may be calculated by multiplying the surface area of the aggregate by ITZ depth. However, in this case, the sum of the volume parts of ITZ $\left(V_{i t}\right)$ and the sum of aggregate fractions $\left(V_{a}\right)$ may be more than 1 . Therefore, this method of calculation is not sufficiently accurate and may be applied only if $V_{a}$ is small. The other technique described in [5] relies on the relationship between the part of the matrix volume and that of the voids, void radius and the depth of the coating around the voids derived by Lu and Torquato [16]. As shown in [17], the relationship offered by Lu and Torquato [16] can accurately define the volume part of ITZ in a composite consisting of matrix and the coated voids. According to [5], the volume part of ITZ of the $i$-th part of mortar may be obtained from the formula:

$$
\begin{aligned}
V_{i t z, i}= & 1-V_{a . i}-\left(1-V_{a . i}\right) \times \\
& \times \exp \left(-\pi \rho_{i}\left(b_{i} R_{i}+d_{i} r_{i}^{2}+g_{i} r_{i}^{3}\right)\right)
\end{aligned}
$$

the coefficients:

$$
\begin{gathered}
b_{i}=\begin{array}{c}
4 R_{i}^{2} \\
1-V_{a, i}
\end{array}, \quad d_{i}=\begin{array}{c}
4 R_{i} \\
1-V_{a, i}
\end{array}+\begin{array}{c}
12 z_{2, i} R_{i}^{2} \\
\left(1-V_{a, i}\right)^{2}
\end{array} \\
g_{i}=\underset{3\left(1-V_{a, i}\right)}{4}+\underset{\left(1-V_{a, i}\right)^{2}}{8 z_{2, i} R_{i}}, \quad z_{2, i}=2 \pi R_{i}^{2} 3,
\end{gathered}
$$

here $V_{a, i}, p_{i}, r_{i}, R_{i}$-volume part of $i$-th mortar portion, amount of particles in volume part, ITZ depth and radius of aggregate, respectively.

Then the volume part of the aggregate of the $i$-th mortar portion and ITZ will be equal to:

$$
c_{i}=V_{i \varepsilon, i}+V_{a, i} \text {. }
$$

When the coefficient $\alpha$ has been calculated for all $i$-th mortar portions, the total $\alpha$ of the mortar may be calculated as an average value of two boundary cases referred to as the cases of Reuss and Voigt $[9,10]$ :

$$
\alpha_{m r t}=\frac{1}{2}\left(\sum_{i=1}^{n} V_{i}^{\prime} \alpha_{m r t, i}+\sum_{i=1}^{n} K_{i} V_{i}^{\prime} \alpha_{m r t . i}\right),
$$

here $V_{i}$ - the volume part of $i$-th portion of mortar, $K_{i}$, $\alpha_{m r t}$ - bulk modulus of $i$-th part of mortar volume and thermal expansion coefficient, respectively.

\section{Results and discussion}

The depth of ITZ is not dependent upon the size of aggregate and $W / C$ ratio, being rather dependent on the size of cement particles, hydration degree as well as on various admixtures in mortar $[11-14]$. The $W / C$ ratio determines the porosity gradient of ITZ $[11,13]$. The lower the W/C ratio, the higher ITZ porosity gradient. With this in mind, a parametric test has been conducted by varying ITZ depth $r$, its bulk modulus $K_{i t}$ and thermal expansion coefficient $\alpha_{i r}$. As shown in [14], the bulk modulus of ITZ may be in the range of $0,2 E_{m} \leq E_{i t z} \leq 5 E_{m}$. According to [18], the Poisson's ratio of cement rock is $v=0,25$, being independent of $\mathrm{W} / \mathrm{C}$ ratio, ie of the porosity as well. According to [19], bulk modulus of cement rock, when $v$ is constant, may be described in this way:

$$
K=K_{0}(1-\Phi)^{3},
$$

here $\Phi$ - porosity and $K_{0}$ - bulk modulus of zero porosity cement rock. In various papers $[20,21]$ we can find that $20 \mathrm{GPa} \leq K_{0} \leq 69 \mathrm{GPa}$. In the present investigation it is assumed that, for cement rock, $K_{0}=30 G P a, v=0,25$.

The depth of ITZ in Portland cement is about 10 $50 \mu \mathrm{m}[9]$. Various researchers $[11-14]$ indicate that ITZ porosity around the aggregate may be by about $24 \%$ higher than that of the matrix. In the present analysis the matrix porosity is assumed to be $30 \%$, then $K_{m}=10 G P a$ and $G_{m}=6 G P a$. For dry hydrated cement rock, ie matrix [22], $\alpha \approx 10 \cdot 10^{-6}\left({ }^{\circ} \mathrm{C}\right)^{-1}$. The porosity of ITZ is $45 \%$, with its bulk modulus $K_{i t-}=5 \mathrm{GPa}$ and $G_{i t^{-}}=3 \mathrm{GPa}$. For aggregate it may be $K_{a}=(20-60) G P a$, depending on the type used, with the thermal expansion coefficient [22] equal to $5 \cdot 10^{-6}\left({ }^{\circ} \mathrm{C}\right)^{-1} \leq \alpha_{a} \leq 8 \cdot 10^{-6}\left({ }^{\circ} \mathrm{C}\right)^{-1}$. A granulometric composition of the aggregate is shown in Fig 2.

The calculations according to the model described have shown that the lower the diameter of the aggregate, the stronger the effect of ITZ (Fig 3). It may be accounted for the fact that when the diameter of the aggregate is decreased, its total surface area is increased as well as the volume of ITZ. The effect of ITZ on the value of the coefficient $a$ is getting weaker at a higher rate than the increase of the aggregate diameter.

This happens because the increase of $V_{i t z}$, with respect to the size of aggregate, is subject to the law of 


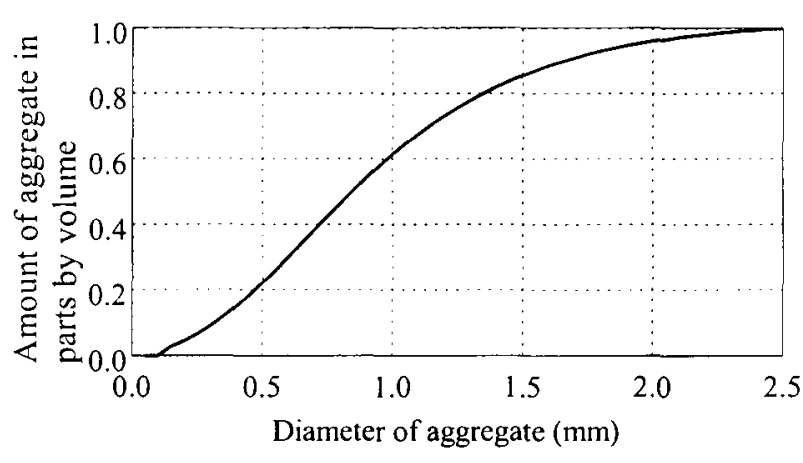

Fig 2. Fractions of mortar aggregate

the exponent [judging from the relationship (9)]. The relationships given in Fig 3, 4 show that the increase of the bulk of aggregate causes the increase of the effect of ITZ depth on the thermal expansion coefficient of mortar. This may also be accounted for the fact that the increase of the aggregate bulk causes the increase of ITZ bulk.

As shown in Fig 4, when the relationship between the bulk moduli of aggregates and matrix varies, the depth of ITZ has practically no effect on the thermal expansion coefficient of mortar. This may be accounted for the fact that when the bulk modulus of matrix or aggre-

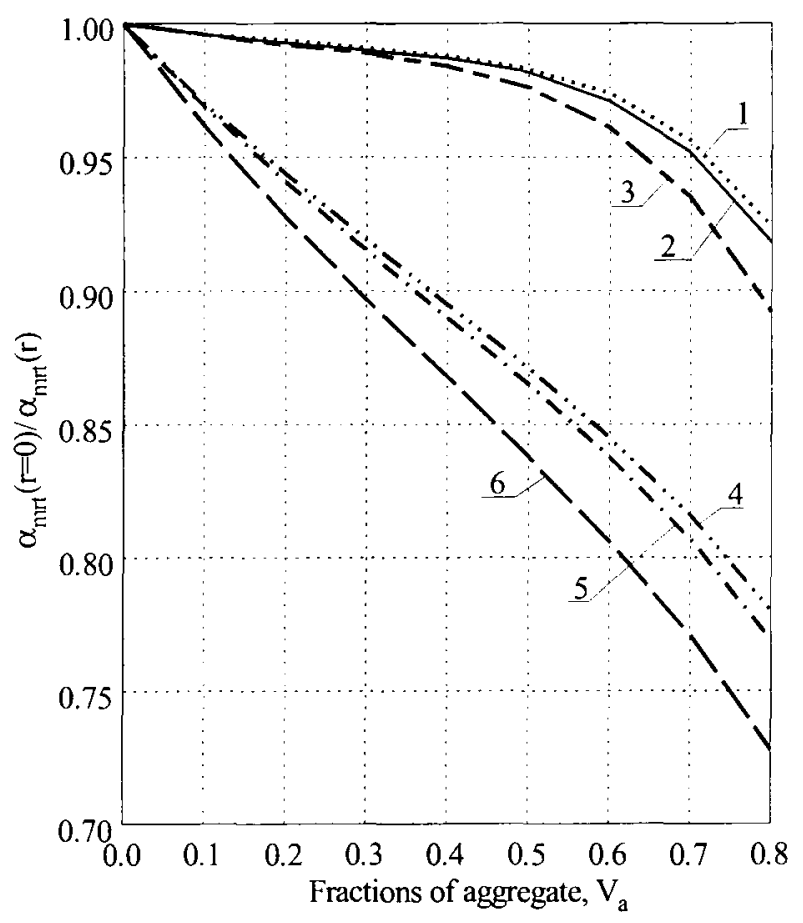

Fig 3. Relationship between coefficient $\alpha_{m r t}(r=0) / \alpha_{m r t}(r)$ and aggregate fraction and ITZ $\alpha$, where $r=50 \mu \mathrm{m}$, $K_{a}=20 \mathrm{GPa}, K_{m}=10 \mathrm{Gpa}, G_{m}=6 \mathrm{Gpa}, K_{i t z}=5 \mathrm{Gpa}$, $G_{i t z}=3 \mathrm{GPa}, \alpha_{u}=5 \cdot 10^{6}\left({ }^{\circ} \mathrm{C}^{1}\right), \alpha_{m}=10 \cdot 10^{6}\left({ }^{\circ} \mathrm{C}^{1}\right): \mathbf{1}, 2$, 3 mortars with $\alpha_{i t z}=\alpha_{m}$ aggregate maximum diameters are 15, 2, 1,2 mm, respectively; 4, 5, 6 mortars with $\alpha_{i r=}=1,5 \alpha_{m}$ aggregate maximum diameters are 15,2 , $1,2 \mathrm{~mm}$, respectively

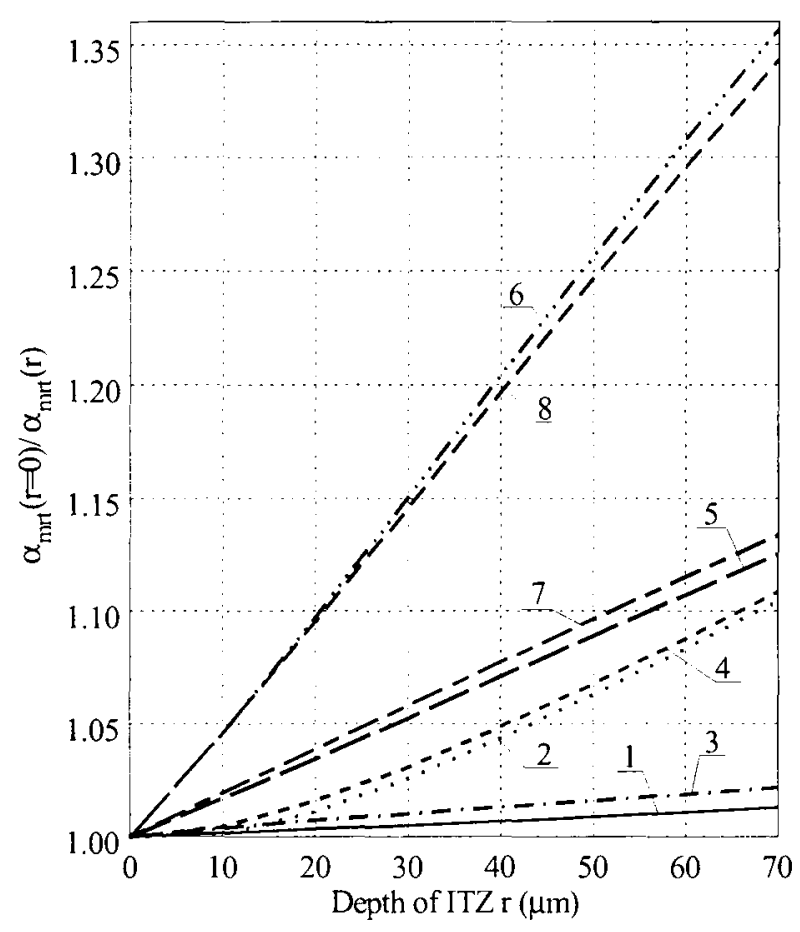

Fig 4. Relationship between coefficient ratio $\alpha_{m r r}(\mathrm{r}=0) /$ $\alpha_{m r r t}(\mathrm{r})$ and depth of ITZ $r, V_{u}, K_{u}$ and $\alpha_{i r t}$, where $K_{m}=10 \mathrm{Gpa}, G_{m}=6 \mathrm{Gpa}, K_{i t=} \stackrel{u^{2}}{=} \mathrm{G}_{\mathrm{apa}}, G_{i t z}=3 \mathrm{GPa}$, $\alpha_{a}^{m}=5 \cdot 10^{6}\left({ }^{\circ} \mathrm{C}^{-1}\right), \alpha_{m}=10 \cdot 10^{6}\left({ }^{\circ} \mathrm{C}^{1}\right): 1-K_{a}=20 \mathrm{GPa}$, $V_{u}=0,3, \alpha_{i t z} / \alpha_{m}=1 ; 2-K_{a} / K_{m}=2, V_{u}=0,75, \alpha_{u t} / \alpha_{m}=1$; $3-K_{a} / K_{m}=6, V_{a}=0,3, \alpha_{i z z} / \alpha_{m}=1 ; 4-K_{u} / K_{m}=6$, $V_{a}=0,75, \alpha_{i t z} / \alpha_{m}=1 ; 5-K_{a} / K_{m}=2, V_{a}=0,3, \alpha_{i t z}$ $\alpha_{m}=1,5 ; 6-K_{a} / K_{m}=2, V_{a}=0,75, \alpha_{i t z} / \alpha_{m}=1,5 ; 7-$ $K_{u} / K_{m}=6, V_{a}=0,3, \alpha_{i t} J \alpha_{m}=1,5 ; 8-K_{a} / K_{m}=6, V_{a}=0,75$, $\alpha_{i t} / \alpha_{m}=1,5$

gate changes, the effect of ITZ on the total bulk modulus of a composite remains practically the same, resulting in slight effect of ITZ on the thermal expansion coefficient. The above data also indicate that the influence of the depth of ITZ increases when the difference between the coefficient a of the matrix or aggregate and ITZ either increases or decreases. This can be explained by the dependence of the coefficient a of the aggregate with ITZ on the coefficient $\alpha$ of ITZ.

With the increase of the bulk modulus of ITZ, the effect of the thermal expansion coefficient varies (Fig 5). At first, when the bulk modulus of ITZ is equal to zero, the coefficient a of mortar is equal to that of matrix, implying that the properties of aggregate have no effect on a of mortar. When the bulk modulus of ITZ sharply increases at the initial stage, with further slower increase, the effect of the coefficient a of aggregate on that of mortar increases (Fig 5). When the ITZ bulk modulus continues to grow, the influence of the coefficient a of ITZ increases to such an extent that it exceeds the effect of the coefficient a of aggregate on that of mortar. With ITZ bulk modulus increasing further, the dependence of the mortar a on ITZ bulk modulus becomes, in fact, linear. With increasing bulk of aggregate, the effect of ITZ 
bulk modulus on the mortar a also grows, increasing more rapidly than in compositions with a small bulk of aggregate (Fig 5). Moreover, when the difference between the coefficient a of ITZ and matrix becomes larger, ITZ has an influence on the coefficient a of mortar even when the value of $K_{i r z}$ is lower (Fig 5). When the depth of ITZ is the smallest, the properties of aggregate and matrix play more important role (Fig 5).
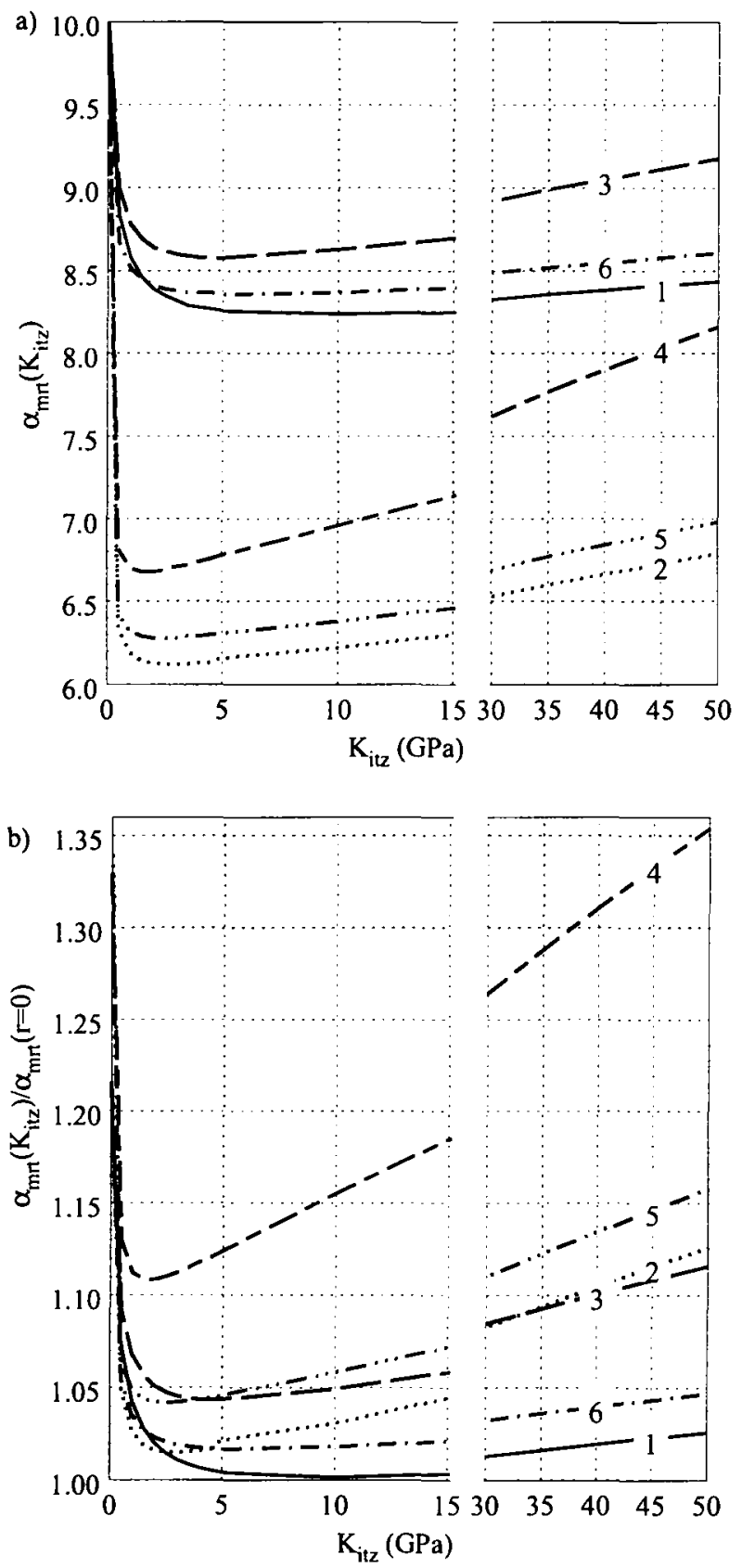

Fig 5. $\mathrm{a}-\alpha_{m \cdot t}$ and $\mathrm{b}-$ the relationship between the coefficient $\alpha_{m r t}\left(K_{i z}\right) / \alpha_{m r r}(r=0)$ and bulk modulus and depth of ITZ, where $K_{a}=20 \mathrm{Gpa}, K_{m}=10 \mathrm{Gpa}, G_{m}=6 \mathrm{Gpa}$ $\alpha_{a}=5 \cdot 10^{6}\left({ }^{\circ} \mathrm{C}^{1}\right): 1-\alpha_{m}=\alpha_{i t}=10 \cdot 10^{6}{ }^{6}\left({ }^{\circ} \mathrm{C}^{1}\right), r=25 \mu \mathrm{m}$, $V_{a}=0,3 ; 2$-same as $1^{m}$ but $\vec{V}_{a}=0,75 ; 3-\alpha_{m}=10 \cdot 10^{6}$ $\left({ }^{\circ} \mathrm{C}^{1}\right), \alpha_{i t}=1,5 i_{m}, r=25 \mu m, V_{u}^{a}=0,3 ; 4-$ same as 3 but $V_{u}=0,75 ; 5-\alpha_{m}=10 \cdot 10^{6}\left({ }^{\circ} \mathrm{C}^{1}\right), \alpha_{i t z}=1,5 \alpha_{m}, r=10 \mu \mathrm{m}$, $V_{u}=0,75 ; 6-$ same as 5 but $V_{u}=0,3$
Generalizing the testing results given in Figs 4,5 , it is possible to state that when the difference between the coefficient $\alpha$ of matrix or aggregate and ITZ grows, the influence of ITZ depth and bulk modulus on the coefficient $\alpha$ of mortar increases as well. The increase of ITZ depth also increases the influence of ITZ properties on the coefficient $\alpha$ of mortar.

The thermal expansion coefficient of fully hydrated

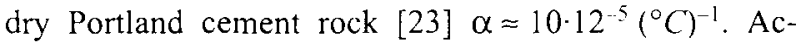
cording to [24], the coefficient $\alpha$ of calcium hydrosilicate is $\alpha=18 \cdot 10^{-5}\left({ }^{\circ} \mathrm{C}\right)^{-1}$, while that of $\mathrm{Ca}(\mathrm{OH})$, is approximately equal to $\alpha \approx(13-18) \cdot 10^{-6}\left({ }^{\circ} \mathrm{C}\right)^{-1}$. The coefficient $\alpha$ of the phase $\beta$ of the basic clinker component $\mathrm{Ca}_{2} \mathrm{SiO}_{4}$ of non-hydrated Portland cement is $\alpha \approx(13-14) \cdot 10^{6}{ }^{\circ}\left({ }^{\circ} \mathrm{C}\right)^{-1}$ [25]. Therefore, in calculating the coefficient $\alpha$ of dry mortars or concretes, the ITZ $\alpha$ may be assumed to be nearly equal to $\alpha$ of cement rock due to a higher concentration of $\mathrm{Ca}(\mathrm{OH})_{2}$ and non-hydrated cement minerals in it. For the materials with equal coefficients $\alpha$ of matrix and ITZ the effect of ITZ on $\alpha$ of the mortar may be neglected (because it is very slight). In this case, concrete or mortar may be considered a composite consisting of two components - matrix and aggregate.

However, cement mortar or concrete are moist under normal conditions. In the interfacial transit zone of higher porosity the proportion of water is also higher, implying that the properties of water or ice have more influence on the value of ITZ coefficient $\alpha$. For water at a temperature of $15^{\circ} \mathrm{C} \alpha \approx 50 \cdot 10^{-6}\left({ }^{\circ} \mathrm{C}\right)^{-1}$, while at the temperature $t=25^{\circ} \mathrm{C}$, the coefficient $\alpha \approx 85 \cdot 10^{-6}\left({ }^{\circ} \mathrm{C}\right)^{-1}$ [26]. Bulk modulus of water $K=2,2 \mathrm{GPa}$ and shear modulus $G=0 G P a$ [26]. For ice $\alpha \approx 50 \cdot 10^{-6}\left({ }^{\circ} \mathrm{C}\right)^{-1}$ [26], with the bulk modulus $K=8,4 G P a$ and shear modulus $G=3,7 G P a$ [20]. In the present test a water-saturated mortar with the matrix porosity of $30 \%, \mathrm{ITZ}-45 \%$ and $K_{a}=35 \mathrm{GPa}$ was considered. Relying on the formulas presented in $[27,28]$ for calculating the bulk modulus of water - saturated rock and the coefficient $\alpha$ and assuming that water can not filter through the pores of cement rock, as well as using the technique described above, the dependence of the coefficient $\alpha$ of wet hardened mortar on ITZ depth under the above-zero temperature was determined (Fig 6). For sub-zero temperature, the bulk modulus of matrix and ITZ with the ice was calculated based on the well known Hashin-Shtrikman relationships by taking the average values, while $\alpha$ was obtained by using Levin's relationship [10]. The coefficient $\alpha$ of mortar was calculated by applying the technique described above (Fig 6).

As we can see from the graphs, water content has a considerable effect on the coefficient $\alpha$ of mortar. The above coefficient of wet mortar or concrete is more dependent on the depth of ITZ than that of dry mortar in Fig 5. This is because the coefficient $\alpha$ of water saturated ITZ due to higher proportion of water or ice in it is not equal to that of water saturated matrix. Ice is most important in determining the value of the coefficient a of mortar because its bulk modulus is higher than that of 


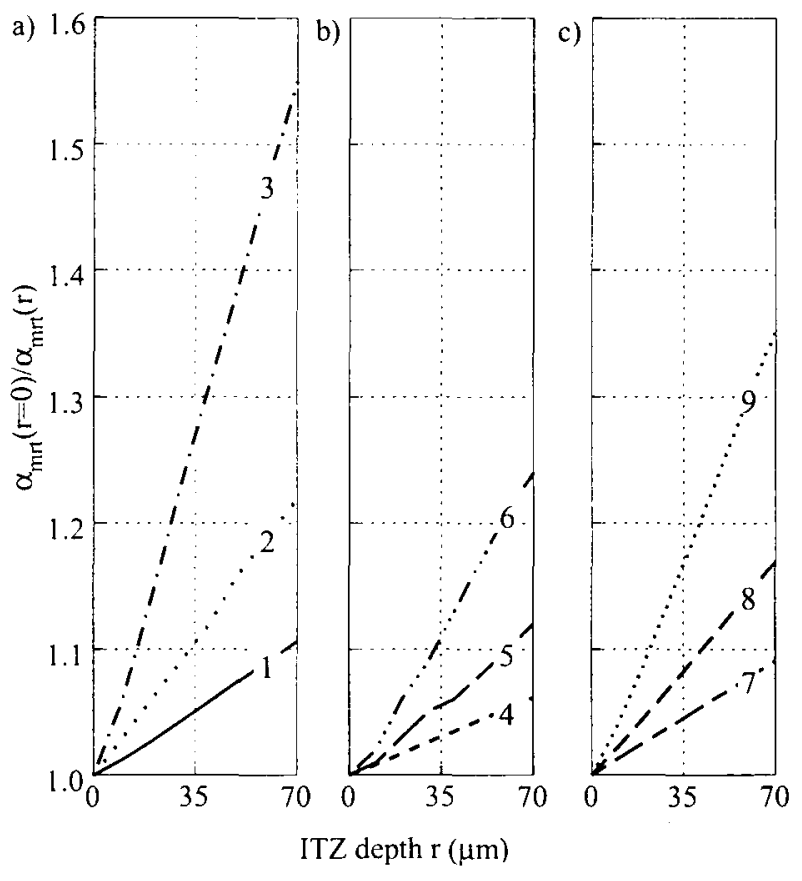

Fig 6. The dependence of coefficient $\alpha$ of wet mortar on ITZ depth, amount of aggregate and temperature: a) ice, subzero temperature: $\mathbf{1}-V_{a}=0,3,2-V_{u}=0,5,3-$ $V_{u}=0,75$; b) $t=15^{\circ} \mathrm{C}: \mathbf{4}-V_{a}=0,3, \mathbf{5}-\stackrel{a}{V}_{a}=0,5, \mathbf{6}-$ $V_{a}=0,75$; c) $t=25^{\circ} \mathrm{C}: 7-V_{a}=0,3, \mathbf{8}-V_{a}=0,5,9-$ $V_{a}^{a}=0,75$

water. This accounts for the great influence of ITZ depth, $K$ and $\alpha$ on the thermal expansion coefficients of mortars and concretes.

\section{Conclusions}

1. Analytical methods for calculating the coefficient of thermal expansion of mortar have been developed.

2. The formulas (5-8) and the analytical approaches to calculating the thermal expansion coefficient have been suggested which take into account mortar microstructure and its basic characteristics.

3. Analytical research has revealed that when the amount of aggregate is increased and the diameter of its components decreased, as well as when the depth and bulk modulus of an interfacial transit zone are increased, the influence of ITZ characteristics on the coefficient of thermal expansion of mortar or concrete is increased.

4. It has been found that the value of ITZ thermal expansion coefficient largely depends on that of thermal expansion coefficient of mortar or concrete.

5. It has been demonstrated in what cases mortar or concrete may be approached either as two- component composite consisting of aggregate and matrix or as a three-component material, containing aggregate, matrix and an interfacial transition zone.

6. The thermal expansion coefficient of water - saturated mortar or concrete is largely dependent on the depth, bulk modulus and thermal expansion coefficient of the interfacial transition zone.

\section{References}

1. Rozenbliumas A. Masonry structures (Mūrinès konstrukcijos). Vilnius: State Publishing house of political and scientific literature, 1956. $443 \mathrm{p}$. (in Lithuanian).

2. Marčiukaitis G. The influence of sudden increase in temperature and humidity on stress-strain states in exterior finishing layer of multiyear walls with flexibilities. Civil Engineering (Statyba), Vol 4, No 3. Vilnius: Technika, 1998, p. 219-226.

3. Roitman A. G. Deformations and flaws of buildings (Деформации и повреждения зданий). Moscow: Strojizdat, 1987. 199 p. (in Russian).

4. Kovler K., Frosting Y. On the problem of cracking in plaster layers. Construction and Building Materials, Vol 12, 1998, p. 251-258.

5. Bentz D. P., Garboczi E. J. Analytical formulas for interfacial transition zone properties. Adv. Cem. Based Mater. Vol 6, 1997, p. 99-108.

6. Hsuen C. H., Becher P. F, Sun E. Y. Analyses of thermal expansion behavior of intergranular two-phase composites. Journal of Materials Science, Vol 36, 2001, p. 255-261.

7. Park C., Kim M., Lee C. A theoretical approach for the thermal expansion behaviour of the particulate reinforced aluminum matrix composite. Part I: A thermal expansion model for composites with mono-dispersed spherical particies. Journal of Materials Science, Vol 36, 2001, p. 3579 3587.

8. Kochetkov A. Calculation of elastic constants and thermophysical properties of multiphase composites with composite or hollow spherical inclusion. Mechanics of composite materials (Механика композитных материалов), Vol 30, No 4, 1994, p. 512-519 (in Russian).

9. Marčiukaitis G. Basic principles of developing composites with predetermined properties in construction (Statybiniu kompozitu kürimo ir savybiu prognozavimo principai). Vilnius: Technika, 1998. 136 p. (in Lithuanian).

10. Berryman J. M. Mixture theories for rock properties. In: Rock physics and phase relations: A handbook of physical constant, ed. T. J. Ahrens, American Geophysical Union, 1995 , p. 205-225.

11. Breton D., Ballivy G., Grandet J. Contribution to the formation mechanism of the transition zone between rockcement paste. Cement and Concrete Research, Vol 23, 1993, p. 335-346.

12. Bentz D. P., Garboczi E.J. Simulation studies of the effects of mineral admixtures on the cement paste-aggregate interfacial zone. American Concrete Institute Materials Journal, Vol 88, 1991, p. 518-529.

13. Bentz D. P., Garboczi E. J., Stutzman P. E. Computer modelling of the interfacial transition zone in concrete. In: Interfaces in cementitious composites, edited by J. C. Maso (E. and F. N. Spon, London, 1993), p. 259-268.

14. Neubauer C. M., Jennings H. M., Garboczi E. J. A threephase model of the elastic and shrinkage properties of mortar. Adv. Cem. Based Mater, Vol 4, 1996, p. 6-20.

15. Li G., Zhao Y., Pang S. Effective Young's modulus estimation of concrete. Cement and Concrele Research, Vol 29 , 1999, p. 1455-1462. 
16. Lu B., Torquato $\mathrm{S}$. Nearest-surface distribution functions for polydispersed particle system. Phys. Rev. A, Vol 45, 1992 , p. $5530-5544$.

17. Snyder K. A. A numerical test of air-void spacing equations. Adv: Cem. Based Mater, Vol 8, 1998, p. 28-44.

18. Simeonov P., Ahmad Sh. Effect of transition zone on the elastic behaviour of cement-based composites. Cement and Concrete Research, Vol 25, 1995, p. 165-176.

19. Neville A. M. Properties of concrete, $4^{\text {th }}$ ed. London, Wiley, 1996.

20. Wanng J. A., Lubliner J., Monteiro P. J. M. Effect of ice formation on the elastic moduli of cement paste and mortar. Cement and Concrete Research, Vol 18, 1988, p. 874885 .

21. Zimmerman R. W., King M. S., Monteiro P. J M. The elastic moduli of mortar as a porous-granular material. Cement and Concrete Research, Vol 16, 1986, p. 239-245.

22. Gorciakov G. I., Liphanof I. I., Terechin L. N. Thermal expansion coefficients and thermal strains of building materials (Коэффишиенты температурного расширения и температурные деформации строительных материалов). Moscow: Publishing House of the Committee of standards, measures and measuring devices of USSR Council of Ministers, 1968. 167 p. (in Russian).
23. Babaev S. T., Dikun A. D., Sorokin U. V. Physical and mechanical properties of cement rock and binders of low water requirement. Building materials (Строительные материалы), № 4, 1991, p. 19-21 (in Russian).

24. Schulson E. M., Swainson I. P., Holden T. M. Internal stress within hardened cement paste induced through thermal mismatch calcium hydroxide versus calcium silicate hydrate. Cement and Concrete Research, Vol 31, 2001, p. 1785-1791.

25. Remy C., Andrault D. High-temperature, high-pressure Xray investigation of dicalcium silicate. Journal of the American Ceramic Societ, Vol 80, 1997, No 4, p. 851-860.

26. Handbook of chemistry and physics. Ed D. R. Lide, 77th ed. CRC Press, Boca Raton, FL, 1996.

27. Dvorkin J., Moos D., Packwood J. L., Nur A. M., Identifying patchy saturation from well logs. Geophysics, Vol 64 1999, p. $1756-1759$

28. Scherer G. W. Thermal expansion kinetics: method to measure permeability of cementitious materials: I, Theory. Journal of the American Ceramic Societv, Vol 83, 2000 , p. $2753-2761$. 